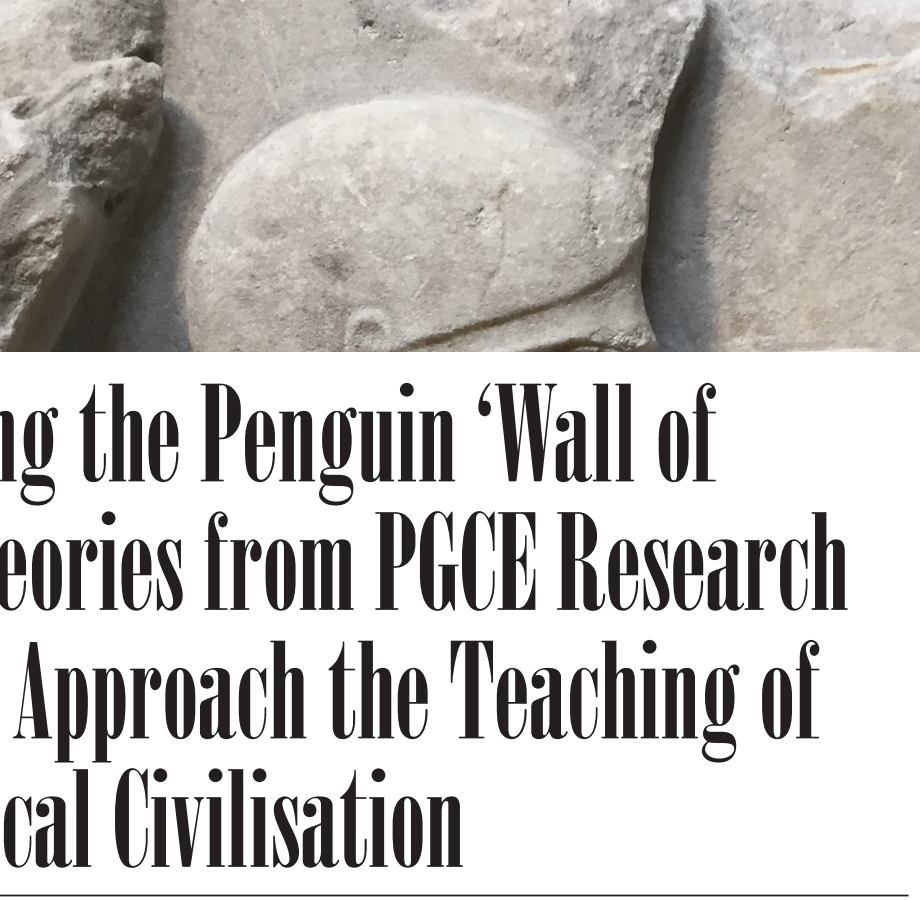

by Rebecca Jones

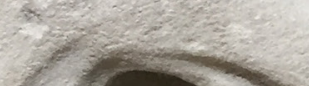

\section{Observation and Theory}

A s my PGCE drew towards its end, $\mathrm{A}_{\text {the prospect of my first teaching job }}$ loomed large in my mind. I had been forewarned that $50 \%$ of my teaching workload would consist of teaching Classical Civilisation, and that the majority of this would be at A Level. However, I did not have personal experience of the subject as a school pupil (I studied Latin, Greek and English Literature at A Level - there was no Classical Civilisation option), so I had no personal frame of reference or preformed opinion of how it might be taught best. The final research project of the PGCE course presented an ideal and much-needed opportunity to investigate the possible teaching strategies I should consider in preparation for my own teaching of the subject. I was particularly interested in how to 'get through' the seemingly vast amount of text which teachers often cited as a real challenge.

In this article I will discuss the various strategies I observed, the teachers' rationales for deploying them, and the students' response to these. First of all though, I summarise key findings from my desk research that explored teaching strategies in the nearest equivalent subject area I could find: the teaching of complex and lengthy texts in KS5 English Literature. From both this and my classroom research, I have developed my own 'theories' on the strategies to employ in the teaching of Classical Civilisation, and the prescribed texts of the literature units in particular. At present, I am attempting to put these into practice in my current role, teaching the Iliad at AS Level and Greek Tragedy at A2. A second, follow-up article will offer reflections on how successful these theories have been in their practical application.

\section{Learning from English Literature teaching research}

I derived four recommendations which could be acted upon from the articles I read about how complex texts might be taught in KS5 English Literature:

1) Accept that you cannot cover everything in class in detail. Carlin (1966) advises: You need not teach everything in the book... a novel or other longer work is sometimes taught successfully with a little judicious skipping.' This is a very different mindset, in my limited experience, to that of the linguisticallytrained Classicist, who seems to be used to analysing original texts in minute detail - as part of A Level Latin, for example. I would need to accept that I could not cover everything in great detail in the time available, nor might this be helpful for students who are already struggling to remember a large volume of information that is completely new to them.
2) One passage: one teaching point.

Teachers should choose one interpretation of a passage and anchor their teaching point on that, because 'you cannot justifiably give a class time to study all facets of a major work' (Carlin, 1966). This indicated to me that it is very important to keep teaching points clear and focused and to resist the temptation to overcomplicate for students with multiple layers of analyses, especially early on in the process.

3) Set reading as homework. Accept that some students will not do it, but put in place strategies to combat this, such as setting overnight tasks that take no longer than 40 minutes. Carlin (1966) contends that the longer some students are given to do the reading, the less likely they are to do it. In addition, try to select materials that will entice students to read and set a brief factual quiz at the beginning of the next lesson to check the reading has been done.

4) Direct the students in what to look for in their reading. The teacher's role is to provide a framework for the student to analyse literature, to practise it with them and then allow them to apply it independently to any text they might encounter. Claus (1964) argues that by discovering texts for themselves, students engage more deeply with the text and remember it better than if 
they are passively 'learning it' from the teacher. As well as being invaluable training for study at tertiary level, this skill is critical in Classical Civilisation examinations where students are required to analyse and comment on a gobbet of text within the wider context of the work.

With these recommendations in mind, I was interested to see what strategies were being utilised in the teaching of Classical Civilisation which I observed.

\section{The Exploratory Research}

The 'classroom' research took three forms, with the objective of drawing out common themes or identifying contradictions between teacher and student perceptions and teacher and student behaviour in the teaching and study of classical texts in translation. The reader should note that PGCE field research requires that students focus on one or two schools, so sample sizes are small and not necessarily representative of the national sample.

\section{1) Teacher Interviews}

I conducted depth interviews with three teachers of KS5 Classical Civilisation and with one teacher of KS5 English Literature. I wanted to understand how teachers perceived the challenges of teaching texts in translation (or complex texts, in the case of the English teacher), how teaching strategies were decided upon, and which strategies and activities teachers perceived work well.

\section{2) Lesson Observations}

I made detailed observations of four lessons where students were studying Homer's Odyssey and 'Greek Historians' for the OCR AS syllabus. In addition, I observed some 30 lessons of Classical Civilisation spanning Years 9 to 13 across three different schools, a grammar school, an independent school and a selective maintained Sixth Form College. Class sizes ranged from 9 to 22 students. This allowed me to understand what teaching strategies were actually being used in the classroom and the students' response to these, what role the teacher performed, how and where texts were read, and in what level of detail. Given the findings from the English Literature research, I was particularly interested in how students were 'trained' to read and analyse texts for themselves.

\section{3) Student Questionnaires}

I wanted to understand the students' perceptions of teaching strategies (or 'learning activities' as I termed them to students): I surveyed 77 students studying KS5 Classical Civilisation across two schools (School A and School B). The 10-minute questionnaire also allowed me to find out which elements of the course requirements they found to be easy and which difficult. In this article I share a brief extract from the wider questionnaire findings.

The timing of my research, during the build up to public examinations, brought with it constraints and forced certain omissions. I subsequently discovered how important the first lessons with the text can be in terms of creating the environment, routines and methods for learning. I could not observe these, so interviews with teachers would have to substitute for this data. Secondly, lesson time with Year 12 and Year 13 students, so close to examinations, was understandably a precious commodity. For this reason, I did not conduct depth interviews with students, although these would have been strongly desirable.

\section{Findings}

\section{1: The Teachers' Perspective}

Challenges

\section{1) The large quantity of text to be covered combined with students' low motivation to read}

Teachers saw the major challenge of the KS5 Classical Civilisation course as the 'sheer quantity' of text to be covered, coupled with the students' 'reluctance to read'. One teacher believed that students lacked an appreciation of reading as an academic skill, seeing reading homework as a 'doss homework'. In many cases, he surmised, this attitude covered up for a 'lack of ability.' A vicious circle could ensue: by giving and being given too much scaffolding students seemed to become 'dependent on the teacher', 'lacked confidence' and as a result 'did not develop their academic reading skills', requiring the teacher to give even more help.

\section{2) Complexity of language used in translations}

The teacher's, often required, role as 'translator of the text' could exacerbate students' over-dependence on her. A teacher commented: 'The translations are not in the English they speak. One student asked me "What is a procession?" when we were discussing the Panathenaic procession.' Another teacher used different translations to help students' comprehension and interpretation, often resorting to the original Latin for enlightenment. She explained, 'Tacitus is so subtle that any translation is only an approximation. Yesterday we had a sentence: He palliated the ingloriousness of his paternity. "What on earth does that mean?" the students said. The texts just aren't as lucid as they could be. They need explaining and I often go back to the original Latin to help.'

\section{3) Students' lack of understanding of the 'context' of the ancient world}

The teacher's role as a supplier of context for the ancient world also featured prominently in interviews. 'Students don't come with a prior knowledge of the ancient world, and if they do it is very specific. We, as teachers, have to supply it.' This is also because students wrongly 'judge ancient texts by modern standards'. In the case of the OCR 'Greek Historians' unit, this constituted providing 'historical context, geography, Greek mythology and the full background to the rise of Persia'. Another teacher felt that boys especially struggled in this area: 'They get hung up on seeing the classical world through computer games, e.g. Achilles as a 'demi-god'. It's a different view, but it's inappropriate terminology and criteria for the ancient world.' 


\section{4) The diraying array of names and myths to be marshalled and memorised}

All the teachers felt that various names, stories and myths were a challenge for students' comprehension and memory. 'In Tacitus, everyone is called Drusus... and then there are all those 'Kings in the cupboard', like Mithridates and

Meerherdates. Very confusing.' Historical literature was also felt to be more challenging for students because it required them to recall a series of often unconnected historical events and characters, whereas literature per se had one story, consistent themes to follow and a core group of characters that stayed with the student throughout the text.

\section{Suggested Solutions}

The teachers' solutions to these issues were quite varied. One felt that 'breaking down texts into smaller sections and getting students to feedback on them' was key. To support this, he argued that it was these passages that he saw quoted most often in the students' essays and therefore this approach seemed to make them stick in students' memories. He also suggested that scaffolding should be decreased over time and that a variety of approaches such as dramatisation and debates, and 'visual versions of stories' were also powerful learning tools. However, he also cautioned that these approaches 'depend a lot on group dynamics'.

Another teacher emphasised the importance of using different teaching strategies and activities to cater for different learners 'to ensure lessons are not monochrome'. For example, for visual learners the group had 'created an image of the dogs eating Priam's genitals (ouch!) in Book 22 of the Iliad, or freeze-frames of the wounds inflicted in the Iliad's battle scenes'. This teacher advocated 'any activities that stimulated long-term memory', given the sheer number of events and characters that need to be learned. She also cautioned against 'death by worksheet', recommending that their appropriate use should be within homework activities.

The English teacher, echoing the articles I had read, impressed upon me the concept of 'training the students' at the beginning of the course to read and analyse texts to avoid teacher dependency and develop academic reading skills. She emphasised the importance of modelling behaviours and techniques in the very first series of lessons and within each lesson. She explained: 'The teacher does it for them, with them, then they do it by themselvesthis should all happen in one lesson... The teacher needs to know the text really well and be able to access it at any point to demonstrate themes, links, structures. The teacher must not meander through it chronologically.' In the Classics classroom, for example, this technique was applied by posting 'purple' passages of Thucydides, Herodotus and Plutarch around the room. Students were given some clues as to writing style, influence, and biographical detail and then had to identify each author.

Having investigated the teachers' perspectives, I wanted to compare them to the actual experience of Classical Civilisation teaching in lessons.

\section{2: The Observer's Perspective}

Teacher-led versus student-led learning?

I observed a number of very different teaching strategies in my lesson observations across two schools: School $\mathrm{A}$ and School B.

A School A teacher adopted the approach of reading through the text aloud in lessons; this was done by the teacher, pupils or a combination of the two, with the teacher giving detailed commentary and providing PowerPoint notes projected onto the board that reiterated the spoken commentary. Some used laptops to make their own notes and copy the teacher's PowerPoint slides. Some students did not take any notes. In other lessons, pupils made notes on worksheets that were designed by the teacher to accompany the text as it was being read. The teacher was absolutely central to the lesson, and analysis of the transcripts showed that $90 \%$ of the talking, explanation and questioning was done by the teacher. On average, this approach allowed three pages of standard 'Penguin Classics' book text to be 'covered' in a 40-minute lesson. I observed no evidence to indicate whether students found the text easily intelligible or not, although the teacher's approach might have suggested they needed considerable help.

The School B teacher's lessons consisted mainly of group work amongst pupils focused on analysis of theme or character. Particular sections of text were honed in on, the teacher posed questions or areas to explore and students were encouraged to process, discuss and play back to the class key themes as arguments or speeches, debates or by using drama. Processes such as xenia, or the stages of a Roman funeral or wedding were literally acted out by students using various props, including a 'sacrificial' toy sheep. Students were asked to compare film clips of key scenes to sections of the text. Reading of the text aloud in a linear fashion during class was literally 'banned', as the teacher put it. Pupils were expected to read an allotted portion of the text, a book of the Iliad for example, for homework and keep track of plot, character and themes in a record book, which was checked by the teacher twice a term. The teacher's role was one of facilitator, questioner and cajoler.

\section{Student Reactions}

I observed a number of specific difficulties that students encountered during the lessons. Characters, their names and the ability to remember them appeared to cause some confusion amongst students. One pupil even asked: 'Are we going to have to remember everyone's names?' Students demonstrated some difficulty in relating to ancient cultural concepts. Athene's aegis was referred to as a 'force-field', for example, and the vocabulary of the world of modern superheroes was used interchangeably with that of Homer's world when discussing the heroic code.

When the students were asked to comment stylistically, they demonstrated some confusion between terms. For example:

Teacher: Nice natural simile there that we've noticed...

Pupil A: (interrupting) It's a metaphor not a simile, 'as vultures'...

Pupil B: It's a massive natural simile.

Pupil A: Simile is 'is' and 'as', and metaphor is...

Pupil B: And metaphor is when you are saying it directly.

Students of historical literature (Tacitus in particular) expressed an 
aversion to the text due to the apparent difficulty of English comprehension. One student made no apology for making her feelings about Tacitus perfectly clear, 'Why do they keep making us read that dreadful book!?' she asked her classmate.

After gathering some idea of students' reactions and views in lessons, I turned my attention to quantitative data on students' perceptions, experience and motivations.

\section{3: The Students' Perspective}

Challenges

The 'amount of set text to read' and 'remembering all of the information' were cited as the most difficult activities in School A. 'Understanding the text' received a spread of answers in terms of difficulty. This led me to wonder if the strategy of reading through the text in a linear way in class contributed to their perception of volume, length and difficulty of text being studied. Strategies that aid memory or create memorable associations around characters are most likely critical for all students, given the challenge of 'remembering all of the information'. 'Understanding the culture of the ancient world' was seen as relatively 'easy' by all but one student. However, the students' ability to do this was not necessarily borne out in the teacher's comments or the lesson observations.

In School B, where a more studentled teaching strategy and a different specification were pursued, 'reading the amount of set text' was seen as a relatively easy activity by well over $50 \%$ of the Y12 respondents. However, they also cited 'remembering all the information required' and 'remembering different characters' as most difficult.

\section{Topic Preferences}

Literature units appear to be enjoyed more by the whole sample, with $81 \%$ of students rating them 4 or 5 (with $51 \%$ rating them 5) for enjoyment and only $5 \%$ 1 or 2 (Table 4), whereas historical units show a greater spread of opinion with $65 \%$ rating them 4 or 5 (26\% rating them $5)$, but $18 \%$ rating them 1 or 2 .

Student verbatims often reflected teachers' comments on why this might be: 'The Iliad was great because it was ONE story and we could keep track of the

\begin{tabular}{|c|c|c|c|c|c|}
\hline \multirow[t]{2}{*}{ Difficulty of Study Skills/Activities } & \multicolumn{4}{|l|}{ Easy } & \multirow{2}{*}{$\frac{\text { Difficult }}{5}$} \\
\hline & 1 & 2 & 3 & 4 & \\
\hline Reading the amount of set texts & 0 & 1 & 3 & 3 & 2 \\
\hline Understanding the set texts & 2 & 2 & 1 & 3 & 1 \\
\hline Understanding literary concepts & 3 & 2 & 4 & 0 & 0 \\
\hline Analysing historical evidence & 4 & 2 & 1 & 2 & 0 \\
\hline Constructing historical arguments & 3 & 2 & 2 & 2 & 0 \\
\hline Studying narrative themes & 6 & 1 & 2 & 0 & 0 \\
\hline Understanding the culture of the ancient world & 5 & 3 & 0 & 0 & 1 \\
\hline Analysing and commenting on visual material & 1 & 4 & 1 & 0 & 0 \\
\hline Remembering all of the information required & 0 & 1 & 2 & 2 & 4 \\
\hline $\begin{array}{l}\text { Remembering different characters (who does } \\
\text { what) }\end{array}$ & 0 & 2 & 2 & 3 & 2 \\
\hline Remembering the plot/key events & 1 & 4 & 2 & 1 & 1 \\
\hline $\begin{array}{l}\text { Remembering how to spell names or places } \\
\text { correctly }\end{array}$ & 2 & 2 & 3 & 1 & 1 \\
\hline Writing essays & 0 & 5 & 2 & 1 & 1 \\
\hline & 27 & 31 & 25 & 18 & 13 \\
\hline Percentage of responses: & $24 \%$ & $27 \%$ & $22 \%$ & $16 \%$ & $11 \%$ \\
\hline Percentage 1,2 and 4,5 combined: & $51 \%$ & & & $27 \%$ & \\
\hline
\end{tabular}

\section{Figure 1.|}

characters throughout'. One Iliad student asserted: 'Everyone loves blood, guts and gods!' and another profoundly

commented: 'War is more interesting than politics'. My tentative conclusion from this is that, if we want students to be motivated to read, 'student appeal' should be a key consideration when choosing which units to teach.

\section{'Learning Activity' Preferences}

Seven out of nine of the School A students felt that they learned most from worksheets, with the other two students citing the video trailer exercise and essay writing as most useful. The verbatims explained further that worksheets helped 'by writing notes on the set texts, they help to remember key themes and events' or 'forces me to engage with the text' and they are 'thorough and written down' and 'very detailed and informative'. None, however, cited worksheets as the most enjoyable activity and, interestingly, of the activity that was enjoyed the most by six students (composing the video trailer of the Odyssey), five of them also thought it was the least useful in terms of learning. I suggest why this might be the case in my conclusion.

In School B the preferences were spread across a wide range of 'learning activities', reflected by the range utilised.

\section{Additional Findings in Brief}

- In School A 100\% of students had studied either Classical Civilisation or Ancient History at GCSE. At School B, only $40 \%$ had any experience of these

\begin{tabular}{|c|c|c|c|c|c|}
\hline \multicolumn{6}{|l|}{ School B (39 students, Y12) } \\
\hline \multirow[t]{2}{*}{ Difficulty of Study Skills/Activities } & \multicolumn{4}{|l|}{ Easy } & \multirow{2}{*}{$\frac{\text { Difficult }}{5}$} \\
\hline & 1 & 2 & 3 & 4 & \\
\hline Reading the amount of set texts & 15 & 10 & 8 & 4 & 2 \\
\hline Understanding the set texts & 4 & 21 & 9 & 5 & 0 \\
\hline Understanding literary concepts & 10 & 16 & 11 & 2 & 0 \\
\hline Analysing historical evidence & 6 & 15 & 12 & 6 & 0 \\
\hline Constructing historical arguments & 5 & 17 & 10 & 7 & 0 \\
\hline Studying narrative themes & 10 & 13 & 12 & 3 & 0 \\
\hline Understanding the culture of the ancient world & 13 & 15 & 9 & 2 & 0 \\
\hline Analysing and commenting on visual material & 5 & 13 & 12 & 7 & 0 \\
\hline Remembering all of the information required & 1 & 3 & 13 & 11 & 11 \\
\hline $\begin{array}{l}\text { Remembering different characters (who does } \\
\text { what) }\end{array}$ & 3 & 11 & 6 & 11 & 8 \\
\hline Remembering the plot/key events & 6 & 10 & 15 & 8 & 0 \\
\hline $\begin{array}{l}\text { Remembering how to spell names or places } \\
\text { correctly }\end{array}$ & 4 & 11 & 11 & 5 & 8 \\
\hline Writing essays & 1 & 13 & 16 & 6 & 3 \\
\hline & 83 & 168 & 144 & 77 & 32 \\
\hline Percentage of responses: & $16 \%$ & $33 \%$ & $29 \%$ & $15 \%$ & $6 \%$ \\
\hline Percentage 1,2 and 4,5 combined: & $50 \%$ & & & $22 \%$ & \\
\hline
\end{tabular}

Figure 2. | 
subjects prior to AS Level. The degree of student familiarity with the subject should therefore determine the teaching strategy, especially at the beginning of the course.

- Encouragingly for teachers, when students were asked why they had chosen Classical Civilisation, the unprompted answers showed that the vast majority of students had selected Classical Civilisation due to an interest in the ancient world, followed by having enjoyed it or performed well at GCSE.

- The most popular subject combination alongside Classical Civilisation at KS5 was English and History.

- The location of the reading of the prescribed texts tended to reflect the teaching strategy, with the majority of School A students claiming to only read in class and the majority of School B students claiming to read at home.

\section{Conclusion}

So what 'theories' did I take forward from this experience that have influenced my own choice of teaching strategy?

Firstly, that the beginning of the course can present an opportunity to 'train' students to read and analyse texts critically, and to enable and encourage more independent discovery and learning, thus discouraging overdependence on the teacher throughout the course. The English teacher's mantra rang in my ears: 'the teacher does it for them, with them, then they do it by themselves- this should all happen in one lesson'.

Secondly, that a combination of the volume of text to be covered and the time needed to practise argument and writing requires that students read the text independently outside lessons. This is not to say that texts should not be read in lessons at all, just that a linear, line by line, read through does not seem practical or desirable in my view. However, specific sections of text should be analysed closely in class where they serve to illuminate themes or character, for example. To do this, the teacher needs to know the text inside out and be able to access it at any point, making links backwards and forwards in the text between themes and character.

Thirdly, not only should a range of teaching methodologies be employed to appeal to different learning styles and abilities, but getting the balance right between teacher-led and student-led activities is an important consideration within that. When considering which activities to employ, the appropriateness of their timing is also critical amongst sixth form students who feel the great pressure of assessment. I hypothesise that activities such as creating video trailers and re-enactment may be received differently by students depending on when they are used. The making of a video trailer may be viewed as a pointless or frivolous activity by students close to exam season, compared to the serious business of worksheets and essay writing. Whereas similar activities done in the autumn term might be embraced more readily by students and can serve as memorable references during revision later on.

Fourthly, the teacher of Classical Civilisation needs to consider how the way we handle the reading of the text can support the development of skills that achieve an end goal of essay writing. The importance of developing writing skills throughout the teaching of the course- not just as part of exam preparation, and the development of argument and evaluation in students' writing has been discussed in this publication by Tombs (1997).

Ultimately, whether we like it or not, KS5 texts are read in order to be analysed and evaluated in written form by the student in exchange for marks and exam grades. Whilst students are tested on their recall of the texts to some degree, the majority of marks at this level are awarded to the quality of written communication of a supported point of view about the text. This is the end goal of the reading and should be incorporated in the teaching strategy throughout.
Finally, the teacher performs an indispensable role as context-setter, interpreter and live 'translator' of both ancient language and ancient culture. It is often the contrast between our modern values and those of the ancients that the Classical Civilisation teacher is required to highlight, and it is often her job to dispel misplaced terminologies, similarities, emotions and empathies that would have had little, if any, relevance for the ancients.

Deciding the appropriate teaching strategy to adopt for KS5 Classical Civilisation, its texts and its students is a challenge: there is no 'magic bullet'. However, as Bolgar (1963) pointed out long ago, it is our job as Classics teachers to find solutions: 'In the final analysis, the whole burden will fall on the shoulders of the teaching profession. If they can develop an approach to their material that chimes in with contemporary interests, classical studies will flourish.' I look forward to reporting back on whether my teaching strategies have 'chimed' with the interests of the students next time.

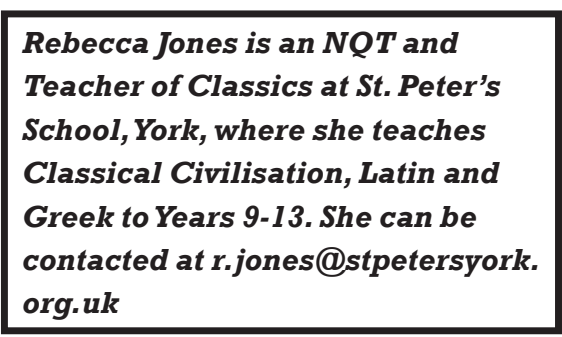

\section{References}

Bolgar, R.R. (1963). A Theory of Classical Education I, Didaskalos I.1, 5-26.

Carlin, J. (1966). A Pattern for Teaching Literature. The English Journal, 55 (3), 291-297.

Claus, L.M. (1964). The Role of Discovery in Teaching Literature. The English Journal, 53 (9), 687-688.

Tombs, S. (1997). Knowledge Tellers or Knowledge Transformers? The Problems of Essay Writing in A Level Classical Civilisation. JCT 21, 10-14. 